\title{
Requirements for Blockchain Technology in Supply Chain Management: An Exploratory Case Study
}

\author{
Ari Sivula \\ School of Technology, \\ Seinäjoki University of Applied Sciences, Seinäjoki, Finland \\ Email: Ari.Sivula@seamk.fi (Corresponding Author)
}

Ahm Shamsuzzoha

School of Technology and Innovations, University of Vaasa, Vaasa, Finland

Email: Ahm.Shamsuzzoha@uwasa.fi

\author{
Petri Helo \\ School of Technology and Innovations, \\ University of Vaasa, Vaasa, Finland \\ Email: Petri.Helo@uwasa.fi
}

\begin{abstract}
The aim of this research study is to look for possible research opportunities to applying blockchain technology in supply chain management and logistics. In addition, accompanying challenges to utilizing blockchain in supply chain management along with possible solutions are also provided. To fulfil the study objective, both theoretical and empirical approaches are adopted for this study. With respect to theoretical approach, relevant literature on blockchain was reviewed considering both technical and economic aspects, its architecture and implementation challenges. The empirical part of the research was conducted by studying three case companies operating in the domains of wood construction, consulting and regional development, and technology. Three case companies were analysed with respect to the application of blockchain in their supply chain operations. From the study outcomes, it was noticed that blockchain technology can be utilized successfully in supply chain management in various business domains in order to provide, for instance, better services and transparency.
\end{abstract}

Keywords: blockchain, supply chain, business opportunities, challenges

\section{INTRODUCTION}

It was found that the application of blockchain technology in various industrial segments is nowadays a growing trend. This technology supports a decentralized digital ledger system that provides trustworthy information exchange between one party and another. This trustworthy decentralized ledger system can be applied to logistics and supply chains to provide mutual benefits. Supply and logistics chains are becoming more digitalized day by day due to the advent of up-to-date technologies. This technological support may ensure dynamic supply chains, where communications among the stakeholders and information exchange can be orchestrated in a real-time environment. Such a real time communication pattern enables the logistics and supply chain to be more transparent to the end users (Addo-Tenkorang et al.,
2012; Addo-Tenkorang and Helo, 2016; Stevens and Johnson, 2016). In order to achieve authentic and real time information exchange between supply chain stakeholders, it is necessary to adopt useful technologies such as sensor-enabling technology, the internet of things and cloud database systems (Morten, 2018). The integration of these technologies with the supply network offers easy access to customer needs through effective sharing of the tracking information of the product or service deliveries. Often this technological integration typically causes high costs with slow diffusion (Korpela et al., 2017). This study researches supply chain and its integration with blockchain technology. This technology can support achievement of disruptive transformation in digital supply chain networks via visibility. Continuous monitoring can be provided with such visibility to ensure improved supply chain performance.

Today's supply chains are inherently complex, consisting of multi-echelon, geographically disjointed entities competing to serve consumers (Saberi et al., 2019). Globalization, government policies, and diverse cultural and human behavior make the evaluating of information and managing risk in supply chains very difficult (Ivanov et al., 2018). Better information sharing and verifiability can overcome such risk, which is caused by inefficient transactions, fraud, pilferage, and poorly performing supply chain management. Traditional transactions of luxury and high value items mainly rely on paper certificates and receipts, which can easily be lost or altered. In fact, lack of transparency in the supply value of any item prevents supply chain entities and customers from verifying and validating the true value of that item. The cost associated with handling such transparency reliably also complicates the managing of traceability within the supply chain. These issues create questions as to whether the existing information systems can support getting the required information for the timely provenance of goods and services in a secure manner, and in a way, which is clear and robust enough to trust (Saberi et al., 2019). The solution to 
these complicated problems can be ensured through improving supply chain transparency, security, durability, and process integrity. Blockchain technology may be the answer to this problem. The concept of blockchain, which is an application of new technological developments and applications, supports these improvement objectives in being more organizationally, technologically, and economically feasible (Swan, 2015; Abeyratne and Monfared, 2016).

Blockchain technology provides a decentralized "trustless" database that permits global-scale transactions and decentralization amongst various supply chain parties (Crosby et al., 2016; Helo and Shamsuzzoha, 2020) and it is making a substantial impact in logistics and supply chain management. Nowadays supply chain managers are starting to recognize the possibilities of this new technology which has high potential to increase transparency in the supply chain (Francisco and Swanson, 2018). In meeting consumers' demands for supply chain transparency, the arrival of this technology seems timely (Francisco and Swanson, 2018). In a supply chain context, transparency refers to the information available to companies related to operationalizing the origins of raw materials and providing the context for final products or services (Skilton and Robinson, 2009). There are several use cases that exemplify the possibilities of and concerns with blockchain technology. For instance, the container management of the Maersk company and its partnership with IBM is conducted cost effectively through blockchains (Groenfeldt, 2017). The management of its sea food supply chain with transparency and the validity of sustainable practices has been conducted by Provence, a blockchain service provider (Steiner and Baker, 2015). The examples show the potential uses of blockchain have been discussed extensively in the literature in terms of the issues associated with environmental, economic or social aspects.

In the case of supply chain management, it is necessary to maintain supplier-customer relationships, process synchronization and data harmonization in a complex, dynamic network that is susceptible to vulnerabilities in a global environment (Wamba et al., 2017). In order to ensure such a relationship, supply chain stakeholders need to consider realtime communication, collaboration, trust and transparency, which yield mutually beneficial outcomes and competitive advantage. Today's advancement of technologies enables faster communication amongst supply chain stakeholders through big data (Addo-Tenkorang and Helo, 2016; Huang and Handfield, 2015; Kache and Seuring, 2017; Barbosa et al., 2018), the internet of things (IoT) (Qiu et al., 2015; Bag et al., 2018; Papetti et al., 2019; Usama \& Ramish, 2020) and blockchain (Mainelli and Milne, 2016; Jordan and Rasmussen, 2018; Kshetri, 2018), amongst others. This study particularly focuses on the application possibility of blockchain technology to improve global logistics and supply chain network. To maintain supply chain integrity, authentication and trust, stakeholders are advancing toward the adoption, development and implementation of blockchain technology as a backbone of their business operations.

Blockchain is a technology, which allows digital information to be distributed and it exists as a shared database, which is not stored in any single location but remains truly public and easily verifiable (Nakamoto, 2008). Blockchain can be applied successfully to execute supply chain management more efficiently. From the three studied cases, it is noticed that there are further opportunities and the potential to apply blockchain in supply chain management. This technology also provides added benefits to different types of projects with respect to the transparency and visibility in the total value chain. Considering the unique features of blockchain technology, the objectives of this study can be formulated as:

1. To analyze the key technical and economic aspects of blockchain

2. To identify the barriers and obstacles to blockchain acceptance in the global marketplace

3. To harness the implementation possibility of blockchain in supply chain management

The paper is organized as follows. Section 2 outlines the literature review related to the basic architecture of blockchain and its application to supply chain management. Research methodology is highlighted in Section 3, while three use cases of blockchain in the supply chain are illustrated in Section 4, along with accompanied opportunities and challenges including various managerial aspects of applying blockchain in the supply chain. The overall research findings are discussed and concluded with future research directions in Section 5.

\section{LITERATURE REVIEW}

The research background and associated literature are reviewed based on basic concept of blockchain, its architecture, and its application in supply chain. During this literature research, focus was given on the operation strategy of blockchain and its suitability to manage global supply chain with respect to transparency, authenticity and trust. During literature research several keywords were used such as blockchain, its architecture, blockchain in supply chain, technical and economic aspects of blockchain and smart contract. Such keywords help to identify suitable and recent references on blockchain technology and its progress so far.

Blockchain is a new technological revolution, basically a growing list of records, called "blocks", which are connected by cryptography (Narayanan et al., 2016). Bitcoin, a first digital cryptocurrency, was first introduced by using blockchain technology in 2008 (Batwa \& Norrman, 2020). This distributed ledger system is typically managed by a peer-to-peer network collectively adhering to a protocol. It consists of blocks of chain, which are marked with a timestamp and are literally tamper-proof (Nguyen, 2016). Each block is considered as a single database, which is then publicly distributed (Sadouskaya, 2017).

There are three types of blockchain namely, public, private and hybrid. The public blockchain allows anyone to participate as users, miners, developers or community members, while in private one, users need permission to join the networks. The hybrid blockchain combines the privacy benefits of a permissioned and private blockchain with the security and transparency benefits of a public blockchain. This kind of blockchain increases the security of transactions and offers benefit from the combined hash-power being applied to the public chains (Bussmann, 2017; Smith, 2020).

\subsection{Basic Architecture of Blockchain}

Blockchain technology is considered as a distributed ledger system, which is the culmination of a decade's work by "an elite group of computer scientists, cryptographers, and mathematicians" (Gupta, 2019). In such a distributed 
ledger system, each party initiates a transaction process by creating a block, which is then verified by multiple computers within the distributed network. This verified block then is considered as the starting point for the consecutive blocks within a chain, and its contents are passed from party to party in the chain. Necessary information within the block is stored across the blockchain in multiple copies, thereby creating an indestructible single unique record. The data or information stored within a block generally can never later be changed or falsified, until and unless by changing or falsifying every single copy of the ledger distributed across the net, which is effectively impossible (Apte and Petrovsky, 2016).
The architecture of blockchain consists of a sequence of interconnected blocks. The basic idea of the architecture is a connected series of blocks using the hash of previous blocks that ensure the integrity of the blocks. Figure 1 presents an example of blockchain architecture. From Figure 1, it is noticed that each block consists of a block header and transaction counter. Each block header is composed of a block version, Merkle tree root hash, time stamp, nBits, nonce and parent block hash.

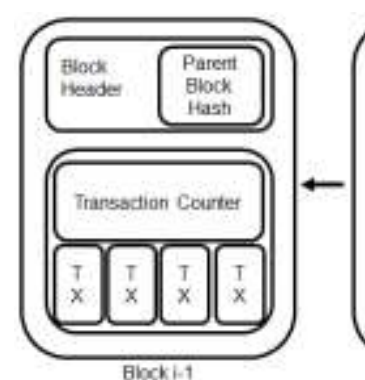

Blockin-1

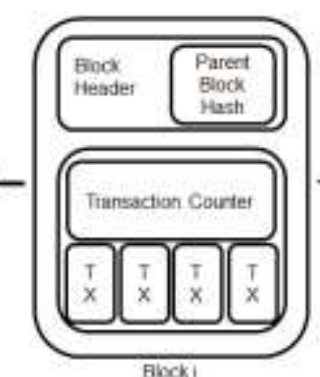

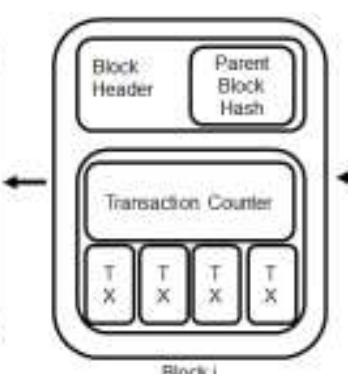

Blocki

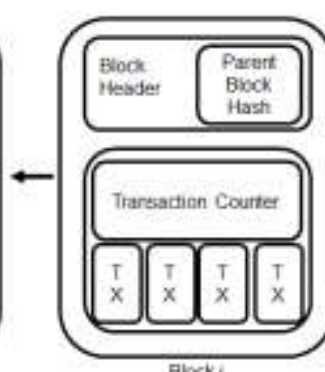

Fickik:

Figure 1 Basic architecture of the blockchain (Zheng et al., 2017)

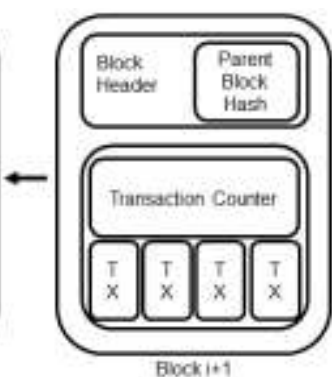

Blockit1
The blockchain is a digital ledger that stores various transaction information publicly after verifies the transaction by nodes. Figure 1 visualizes the basic structure of the blockchain technology. Each of the transaction within the blockchain is validated by the nodes. All the transactions are secured by using the hash function, which is cryptographically protected. Any transaction is connected by its previous transaction through its hash value (Tama et al., 2017). In this way, transactions are securely integrated with each other and maintains its authenticity. Due to such security pattern, once a transaction is added to the blockchain no one can modify or alter it. In addition to such security of transaction, blockchain also uses some of the concepts such as proof of concept and proof of work as well as proof of stake concept to validate the transaction (Mohanta et al., 2018).

\subsection{Application of Blockchain in Supply Chain Management}

Delivering and producing goods involve several points and, therefore, have several stages and locations. Several challenges exist in supply chain networks related, for instance, transparency and performance monitoring. These can cause several problems like misunderstanding between organizations (Burgess et al., 2006; Williams, 2015). Tracking of the products and goods are important for customers and these problems can be a major issue, for instance, in quality and condition monitoring (Dickson, 2016). Quality management is crucial in supply chains (Shaiq et al., 2020). Fast data distribution between different organizations creates transparency between organizations and, therefore, improve the efficiency in the supply chain networks. The utilization of blockchain provides transparency and security for logistics, which have been seen a good solution (Earls, 2016). The blockchain technology provides an excellent traceability features for logistics (e.g. goods and different items) easily even with simple applications. Product and service tracking is possible in several ways. All organizations in supply chain can participate due the technological nature of blockchain. Security is as well in an excellent level because of blockchain's immutable technology.

A technology like blockchain further facilitates the achieving of real-time granular visibility, ensures trust, and enforces security using a chronological order of transactions verified by a unique spendable crypto-digital currency, such as bitcoin. Figure 2 and Figure 3 display traditional and blockchain-based supply chain management respectively (adapted from Saberi et al., 2019). From Figure 2, it is seen that in traditional supply chain networks, the process starts with materials suppliers, which is followed by the manufacturer, distributors, wholesalers, retailers and consumers. The information flow transmits sequentially from materials suppliers to consumers.

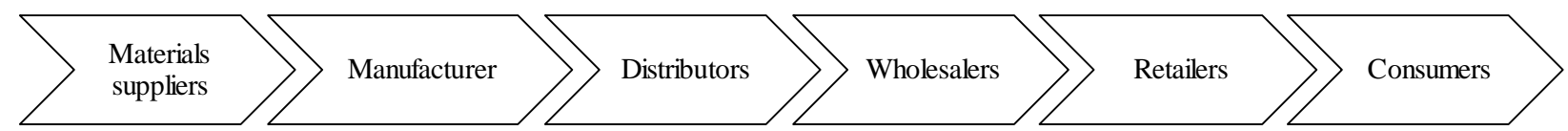

Figure 2 Traditional supply chain management 


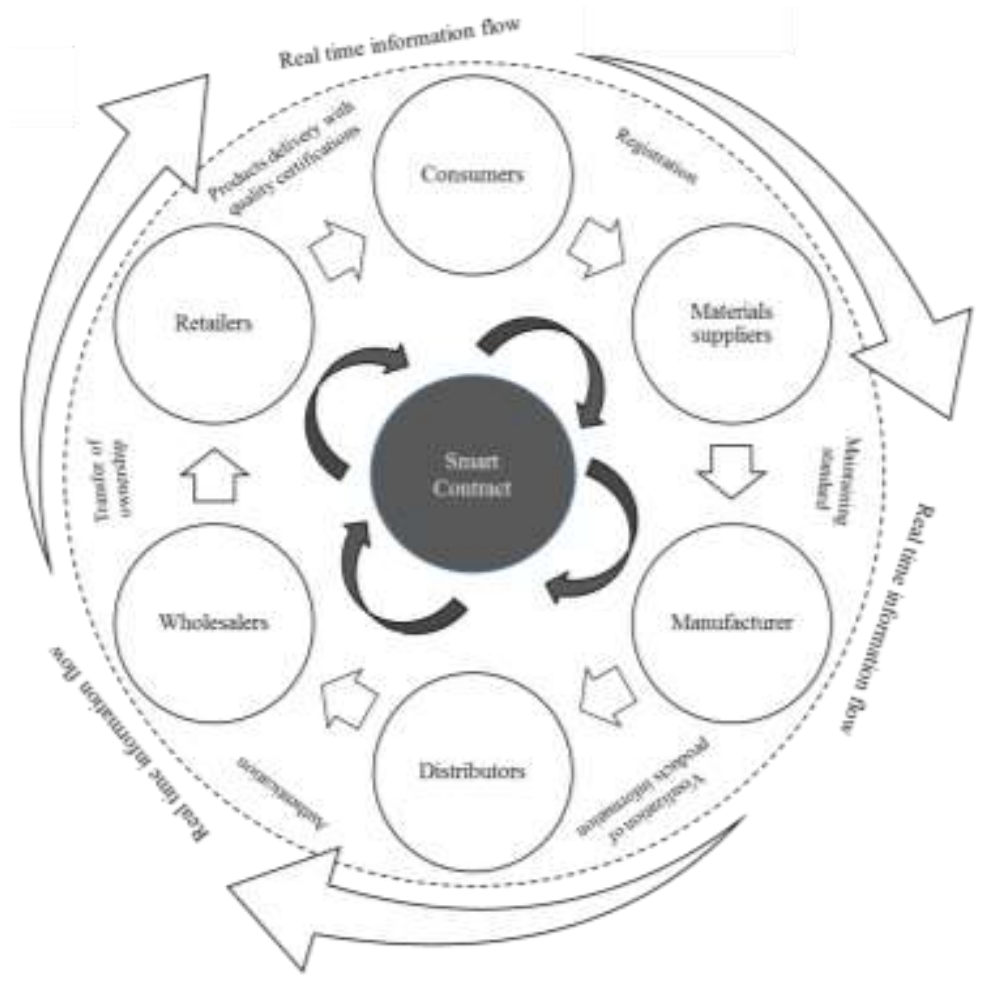

Figure 3 Blockchain-based supply chain management (adapted from Saberi et al., 2019)

In the case of a blockchain-based supply chain network, there are six major entities playing a role which are not seen in the traditional supply chain network. The six entities are registration, maintaining standard, visualization of product information, authentication, transfer of ownership and product delivery with quality certifications. The registration process provides unique identifications to each of the actors in the supply chain, while maintaining standard entity ensures the standard of the supplied products following blockchain policies and technical requirements. All necessary information of the supplied products is visualized with the necessary authentication process as seen in Figure 3. In a blockchain-based supply chain, ownerships are transferred between supply chain actors, including manufacturers, retailers and consumers (Saberi et al., 2019). Final products are delivered to the consumers with quality certifications as provided by the standard organizations (Steiner and Baker, 2015).

In blockchain-based supply chains every product may have a digital identification to ensure that all relevant supply chain actors can have direct product profile access. This product identification process provides the necessary security measures with the correct digital keys to have access to a product. This digital key works as an information tag attached with a product, which represents an identifier that links physical products to their virtual identity in the blockchain (Abeyratne and Monfared, 2016). In order to access a product's profile and to transfer or sell a product to another actor in the supply chain, there may be a need to sign a digital contract between both actors. This digital sign is managed by an entity known as a smart contract, which ensures the necessary permission following agreements and consensus among supply chain actors. Smart contracts help to maintain interaction amongst the supply chain actors and within the system. Smart contracts support network data sharing between supply chain actors and continuous process improvement.

In a blockchain-based supply chain, smart contract governance and process rules can manage the supply chain actors by providing certification and approval. Such certification and approval allow supply chain actors to have access and to execute necessary processes, which are mainly dependent on the supply chain type. The supply chain actors cannot change the rules required for certification and approval without some form of consensus process (Maurer, 2017). In addition to supply chains, applications of smart contracts are seen in the procurement segment. In the case of purchasing, two trading partners can legally update the automated record of what goods were bought, sold, and delivered in real-time through a smart contract. A smart contract has great potential in terms of the continuous improvement of supply chain processes, design and real-time implications, beyond just product delivery and governance concerns (Saberi et al., 2019).

\section{RESEARCH METHODOLOGY}

This research follows the standard case study procedure introduced by Yin (2014) and is based on case studies and concluded by a multi-case study. A multi-case study makes it possible to draw conclusions from a set of cases and is useful for examining the phenomena that occurs in a variety of situations (Gagnon, 2010). This research can be concluded as a piece of qualitative research and the data was collected utilizing semi-structured interviews. All the respondents were recruited to the research by using phone and based on their background. One key person per company was interviewed and one interview took around one hour. The inter- 
view questions were focusing on the motivation of the company towards blockchain technology. The interview questions were highlighting, for example, the blockchain as a technology, added value for the organization and its markets and the usability of the blockchain. The respondents were managers and they had a technological background including the degree. The unit of analysis is the case company and its processes.

The usability of blockchain was researched in three case companies in Finland and Italy. The main goal was to analyze how the case companies' management considered

using blockchain in their daily operational activities. Mainly two areas of the case companies' operational activities were emphasized in terms of fitting blockchain technology, namely financial services (e.g. trade finance) and supply chain (e.g. traceability and transactional services). These case studies were adopted on a macro-level business case view in terms of the potential of blockchain technology, which is still being developed and piloted. Background information on the three case companies is presented in Table 1.

Table 1 Background information of the three case companies

\begin{tabular}{|l|c|c|c|}
\hline \multicolumn{1}{|c|}{ Industry } & Wood construction & $\begin{array}{c}\text { Consulting and regional de- } \\
\text { velopment }\end{array}$ & Technology \\
\hline Country & Finland & Finland & Italy \\
\hline Employee count & 20 & 42 & 5 \\
\hline Utilization of blockchain & No & Yes & Yes \\
\hline Purpose of utilization & - & $\begin{array}{c}\text { Testing and piloting (technol- } \\
\text { ogy diffusion) }\end{array}$ & $\begin{array}{c}\text { Core technology (blockchain } \\
\text { product) }\end{array}$ \\
\hline
\end{tabular}

Cases were selected based on their knowledge and utilization levels or possibility to utilize the blockchain. Moreover, case companies were selected based on their activities and technological development objectives. The three case companies are adopting blockchain or are planning to utilize the technology soon. The case companies are striving to utilize blockchain in various ways in their supply chain management, even though currently there are no specific procedures or standards for its implementation. Selected case companies are small, but they are acting in the industries, where the blockchain can provide business value. Moreover, these companies actively seeking value of blockchain technology in the supply chain.

The analysis was implemented with standard qualitative analysis procedures based on the transcript text, where the coding was implemented on the themes for finding the possibilities and challenges. The approach is inductive because data was utilized to define the themes (possibilities and challenges).

The aim of these three case studies was to explore the potential value for blockchain technology adoption and usage across their various business domains. The studied companies have shown their interest in applying blockchain in their supply chain as a means of identifying and tracking all assets throughout the supply chain. It is believed that due to blockchain being an immutable chain of transactions, each delivery can be completely and securely tracked and traced in order to prevent any errors in the supply chain system.

Table 2 Use case of blockchain in the wood construction industry

\begin{tabular}{|l|l|}
\hline \multicolumn{1}{|c|}{ Stakeholder } & Utilization of blockchain \\
\hline $\begin{array}{l}\text { Forest owners and associ- } \\
\text { ations }\end{array}$ & $\begin{array}{l}\text { Records and reads data concerning the forest and its condition (e.g. positioning and wood type). Utilizes } \\
\text { the data to implement enhanced forest planning based on the needs in the value chain. }\end{array}$ \\
\hline Preliminary processing & $\begin{array}{l}\text { Saves data concerning the wood material and its processing (e.g. batch, length, width and weight). Reads } \\
\text { and records data concerning the agreements and contracts. }\end{array}$ \\
\hline
\end{tabular}

\section{USE CASES OF BLOCKCHAIN IN THE SUPPLY CHAIN}

Blockchain can be utilized in various ways in the supply chains. The blockchain-based supply chain maintains a standardized form, otherwise it will be hard to maintain the required communications between the actors (e.g. persons, machines and systems). All parties within the supply chain maintains predefined access rights to the blockchain, but the usage roles can be different. Thus, the access right to the blockchain can be distributed in the sense of requirements. In addition, data from other sources such as IoT devices that deliver sensor data can be directly imported to the blockchain.

This type of standardized blockchain for the supply chain can provide flexibility, transparency and trust between the actors. Moreover, blockchain can also provide added value for the end customer of the product or service. Companies can launch new business models and services based on the data in the blockchain. Furthermore, the data can be utilized as well as analyzed with machine learning algorithms with the objective of providing deeper analysis for companies which are part of the blockchain platform.

This research was concentrated on three different industries. Utilizing the results of the study, the cases are constructed for each industry. The wood construction industry and its actors can utilize blockchain in various ways, as presented in Table 2.

\section{Utilization of blockchain}


Table 2 (con $`$ ) Use case of blockchain in the wood construction industry

\begin{tabular}{|c|c|}
\hline Stakeholder & Utilization of blockchain \\
\hline Logistics & $\begin{array}{l}\text { Sets the transportation data (e.g. position and tracks) and quality data related to the material (IoT) to the } \\
\text { blockchain. }\end{array}$ \\
\hline Architects & $\begin{array}{l}\text { Records and reads the plans for the buildings or other infrastructures. Utilizes the data in the blockchain } \\
\text { in planning of infrastructures. }\end{array}$ \\
\hline Production & $\begin{array}{l}\text { Reads the documents (or direct links to the documents) related to the blockchain (e.g. plans). Produces, } \\
\text { for example, the construction elements based on the data at the blockchain. Records the wood processing } \\
\text { data (e.g. wood type, other material utilized, processing time, plans and data concerning the process). }\end{array}$ \\
\hline $\begin{array}{l}\text { City officers and govern- } \\
\text { ment }\end{array}$ & $\begin{array}{l}\text { Utilizes the data in the blockchain in city planning and provides the information concerning the plans in to } \\
\text { the blockchain. }\end{array}$ \\
\hline Construction companies & Reads the information concerning the building or other infrastructure while construction. \\
\hline End user or owner & $\begin{array}{l}\text { Provides first stage data concerning the building or infrastructure, which is distributed among the actors in } \\
\text { the chain. Reads the historic data concerning the building or infrastructure. Reads and records data con- } \\
\text { cerning the agreements and contracts. }\end{array}$ \\
\hline $\begin{array}{l}\text { Renovation and other } \\
\text { companies }\end{array}$ & $\begin{array}{l}\text { Reads the historical data of the building (e.g. technical data) or other infrastructure and utilizes this infor- } \\
\text { mation in renovation process. }\end{array}$ \\
\hline
\end{tabular}

The wood construction industry use case is one example of the complex utilization of blockchain, which provides value for all companies which are part of the value chain. Commonly, initiative is made by the customer in the wood construction industry. This type of blockchain also provides a new platform for innovations in the construction industry. The second use case is consulting and regional development and is presented in Table 3.

Table 3 Use case of blockchain in the consulting and regional development industry

Table 3 Use case of blockchain in the consulting and regional development industry
\begin{tabular}{|l|l|}
\hline \multicolumn{1}{|c|}{ Stakeholder } & Utilization of blockchain \\
\hline Company & Management and distribution of different contracts. Overall development of blockchain solutions. \\
\hline Marketing & Customer relationship management and marketing activities within the company. \\
\hline Consultant & Customer background information utilization as part of the consulting process. \\
\hline Customers & Management and distribution of different contracts. \\
\hline
\end{tabular}

Consulting and regional development companies are be able to utilize blockchain in various ways, depending on the industry the company is acting on. The consulting and regional development company was acting as a developing and innovation diffusion company for blockchain solutions in the supply chain. The third use case company is a technology company, which is also developing blockchain as its core technology, and its basic information is outlined in Table 4.

Table 4 Use case of blockchain in the technology industry

\begin{tabular}{|l|l|}
\hline \multicolumn{1}{|c|}{ Stakeholder } & \\
\hline $\begin{array}{l}\text { Development and manu- } \\
\text { facturing company }\end{array}$ & $\begin{array}{l}\text { Development of blockchain technology in the supply chain and management of different contracts. New } \\
\text { innovative costumer solutions utilizing the blockchain. }\end{array}$ \\
\hline Subcontracting & $\begin{array}{l}\text { Sharing documents and plans between different stakeholders and other actors which provide value for a } \\
\text { new technology. }\end{array}$ \\
\hline Marketing & $\begin{array}{l}\text { Utilization of the data which is part of the blockchain as marketing operations. Utilization of blockchain part } \\
\text { of customer relationship management. }\end{array}$ \\
\hline $\begin{array}{l}\text { Distributor of the technol- } \\
\text { ogy }\end{array}$ & $\begin{array}{l}\text { Ordering the products from the company which is developing and utilizing blockchain in operations. Man- } \\
\text { agement of different contracts and agreements between the stakeholders. }\end{array}$ \\
\hline $\begin{array}{l}\text { Retailers and other prod- } \\
\text { uct sellers }\end{array}$ & $\begin{array}{l}\text { Receiving the data concerning the technology. Management of different contracts and customers. Record- } \\
\text { ing and reading the data about warranties of the products sold. }\end{array}$ \\
\hline Customer & Utilizing the data which is in the blockchain related to the technology purchased. \\
\hline
\end{tabular}

The technology company, which is developing the blockchain solutions can act as a user of the blockchain technology. The services offered via the blockchain can provide useful insights to the technology companies to maintain their supply chains. Data can be used, for instance, to provide 
more customer-centric products which connect the end user to the technology developer and manufacturer.

\subsection{Results and Methodologies of the Business Case Studies}

This section presents the research results and provides methodologies of the case studies. Moreover, managerial implications are presented in this section based on the results of the study.

\subsubsection{Opportunities in the Blockchain}

Several opportunities are existing for the Blockchain technology in logistical networks and chains. New business possibilities are opened, and existing ones can be improved. This study provides possible development directions for blockchain technology and businesses in logistical networks. Figure 4 illustrates several opportunities of the blockchain technology based on multi-case study

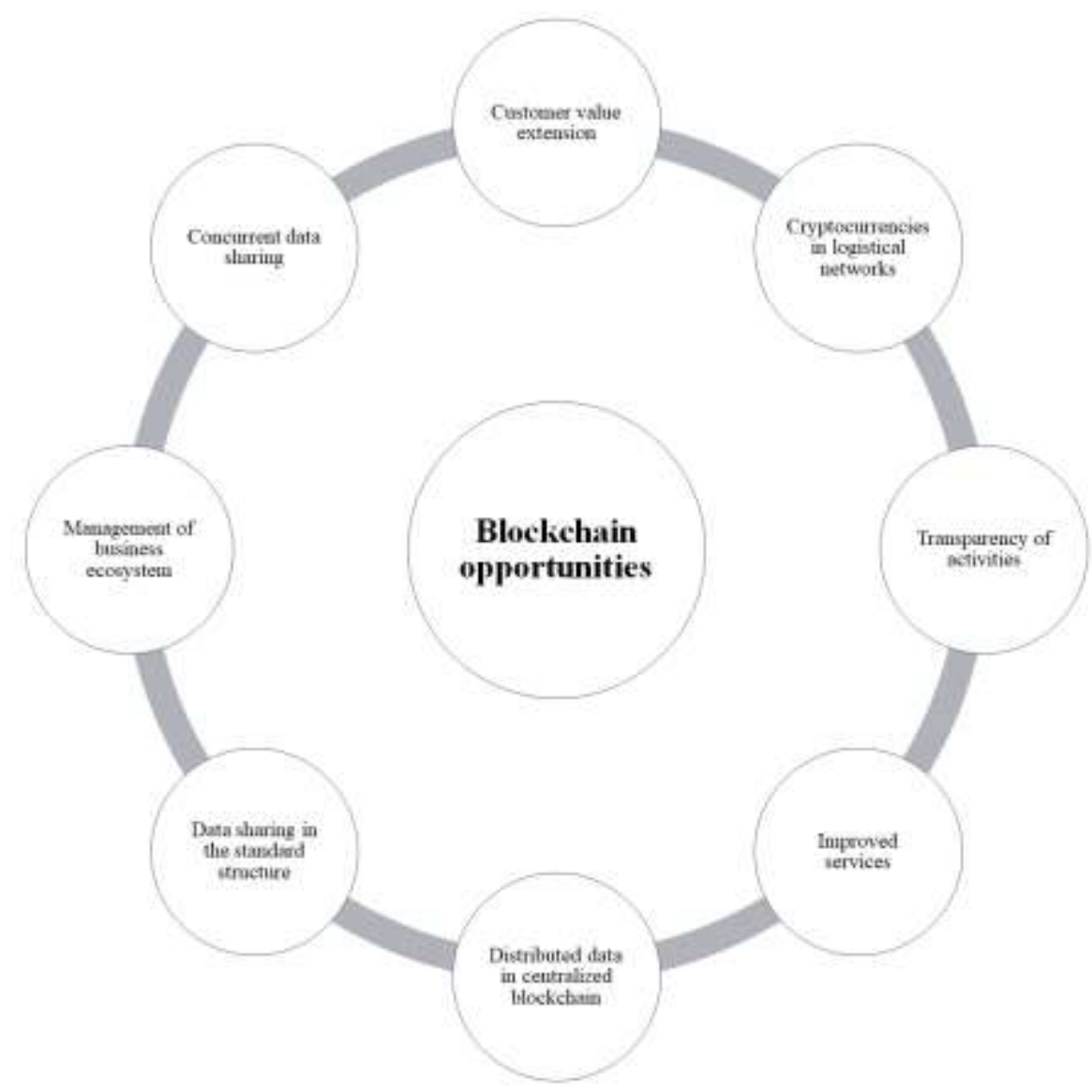

Figure 4 Opportunities of blockchain technology

Blockchain technology provides possibility for customer value extension. The digital ledger system provides possibility for recoding the data from the supply chain. This type of system can provide valuable information and services for the end user. Examples these are recording the process of construction, reporting the current status, costs of the wood construction item in the supply chain and following the process of construction from the very beginning. Moreover, this same data can also be adapted between different organizations in the supply chain. Privacy should be a concern and it should be on a high level and the user roles should be clear to all parties in blockchain.

Cryptocurrencies can be integrated into the logistical networks to provide added value. Cryptocurrencies, like Ethereum, provide a several ways to transfer currency be- tween different organizations. Bank involvement is not necessary in the payment process. Cryptocurrencies can be utilized in immediate transaction, for instance, after every phase in the logistic chain. For instance, the international sales would benefit this type the process. Only several special cryptocurrencies could be utilized in this type of activities (e.g. supply chain cryptocurrency). However, some respondents in the study did not acknowledge the connection between cryptocurrency and its utilization while using blockchain as a part of logistical activities.

Blockchain technology provides transparency of activities, which is an important issue when several organizations are part of the supply chain. Several organizations are linked together via the blockchain technology including the customer, which provides procedure to manage the entire logistic blockchain. Transparency does not mean that everybody in 
the blockchain have a full access to all information included in the blockchain. Thus, privacy should be a main concern even though transparency is important.

Maintenance is commonly required by different infrastructures and, thus, several organizations are required these activities as well. Improved services can be provided by the several organizations to the customer during and after construction process. The blockchain data is required to be in a high level and, therefore, it should be accessed only by the request of the customer. This data can be utilized, for example, in renovation projects. The customer can give a single access to the blockchain for several organizations that can be benefit this information in renovation project. Same type of procedure can be adapted in construction when several organizations are involved in the process.

A large amount of data is required, for instance, by the buildings and infrastructures. This data can be, for instance, plans, reports, CAD models and contracts. This type of a data cannot be included directly to the blockchain, but it can be implemented with direct links to external systems, which are owned by different organizations. This type of implementation is distributed data in centralized blockchain. Therefore, this type of blockchain acts as a concentrator of several systems and includes an information where the final data is located. The blockchain can contain transaction information and blockchain development should be holistic in different logistical solutions, because all different point of views should be covered.

Data can be represented in various formats in multiple systems. One of the biggest benefits in logistics networks is that data can be shared and distributed in standard format. This provides several possibilities in logistics, for instance IoT based data systems and documents. Smart sensors can insert the data directly to the blockchain, which can then be utilized by all the actors in the logistic network. Moreover, other documents and links can also be distributed through the blockchain. On the other hand, all parties should share the same schema and follow the same processes while utilizing the blockchain.

Blockchain provides a new way to manage the business ecosystem. All parties can take part in the logistics network and, therefore, manage their own activities during the logistics processes. The receiver, transporting companies, sender, and other companies can see the status and other information related to the process in real time and adjust their processes based on the logistic network status. Therefore, the entire business ecosystem will gain benefit based on the information provided through the blockchain.

Blockchain provides a possibility for concurrent data sharing. Organizations which are part of the logistical blockchain system can get the same data, which increases transparency. Data fidelity is also increased via the blockchain, and the data can be analyzed with machine learning algorithms. Accuracy is also to be maintained at a high level because of the blockchain architecture.

Private blockchains would provide the most of benefits for different organizations based on the case studies. This has a direct relationship for the data privacy. Thus, privacy and security levels should be one of the main concerns during the development. More piloting and testing are required to be sure about the major risks of utilization of blockchain in supply chain networks.

\subsubsection{Challenges in the Blockchain}

Challenges in the blockchain also exist, even though there are a lot of opportunities and possibilities in its utilization in various industries. Figure 5 summarizes the challenges of blockchain technology based on this multi-case study.

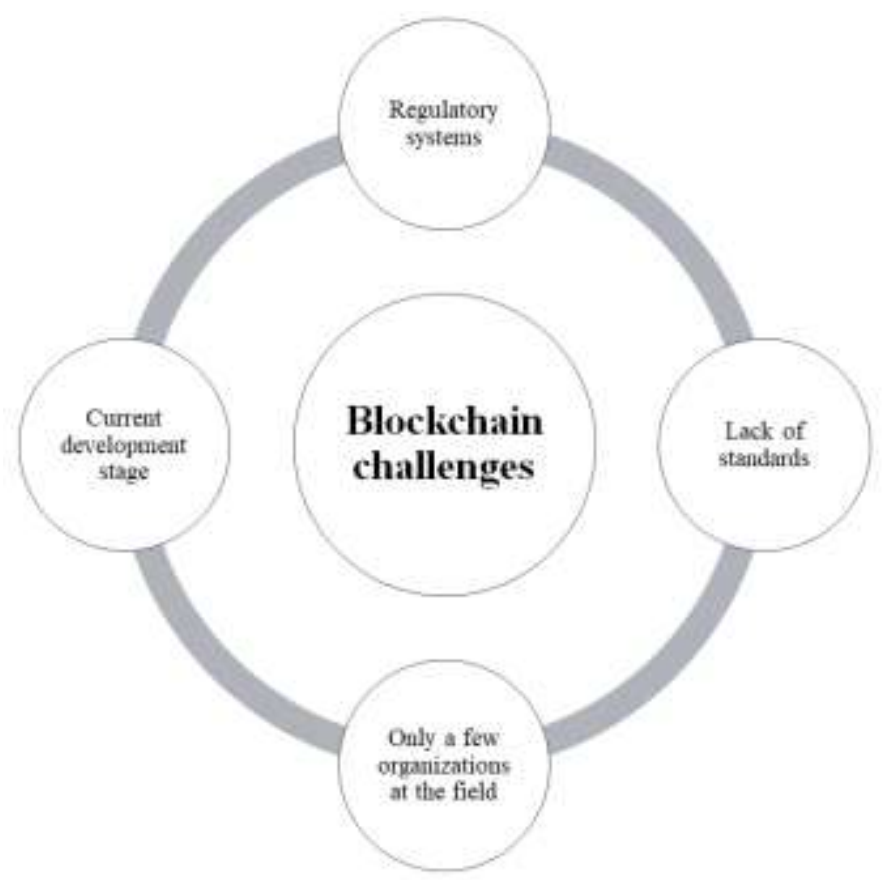

Figure 5 The challenges of blockchain technologies in logistics 
The first major challenge is that currently there are no specific regulations or laws for blockchains. Public organizations and government should provide some regulations, even though the blockchain can be owned by private organizations. These can be, for instance, some basic information concerning the parties participating in blockchain and its utilization. For example, the government of the country may authenticate the company and ensure its identity through their own systems to keep the information accurate. Otherwise, there might be some security issues concerning the identities of the companies.

The second major challenge is that there is no specific standard for blockchain structure. One major standard provides benefit for all actors in the field because of interoperability of different systems. Thus, a single blockchain schema should be selected for logistic activities in order to provide appropriate development possibilities for the field. An example of a schema standard which was utilized in the case organization is the UBL schema, which can be utilized in several ways in logistical blockchain activities.

The third challenge is that there are only a few organizations at the field who are currently developing blockchain in logistics. Involvement of more actors may provide extended benefits for the development of blockchain technology in logistics. Thus, more piloting and testing is required to make the technology and the model more effective and usable in business ecosystems. More use cases are required to make the technology more attractive for different types of organizations.

The fourth challenge is the current development stage. Blockchain in logistics is currently at the idea stage more than the production stage, even though testing and piloting are currently being implemented with blockchain based on the interviews conducted in this research. Thus, it can be concluded that more research and development is required to make blockchain technology more effective in various areas.

\subsubsection{Managerial Implications}

Through implementing blockchain technology, supply chain managers can monitor and evaluate their products, services and carriers, which helps them in their decision making. The risk of respect to fraud of falsified products is reduced with blockchain and exchange of payment systems are simplified (Nakamoto, 2008; Hancock and Vaizey, 2016). Moreover, blockchain technology brings forecasting, optimization and forward visibility in supply chain networks (Lieber, 2017). Various processes within the supply chain such as production, shipping and delivery, order fulfillment, distribution, invoicing and payment can be integrated by this technology (Matthias et al., 2017). This integration of technology offers businesses increased flexibility by capturing the total value chain that the stakeholders have invested in at any point along the supply chain network (MacCarthy et al., 2016; Richey et al., 2016).

By implementing blockchain technology, supply chain managers are able to highlight at least five key product dimensions: the nature (what it is), the quality (how it is), the quantity (how much of it there is), the location (where it is) and the ownership (who owns it at any moment) (Saberi et $a l ., 2019)$. In this way, this technology removes the need for a trusted central organization that operates and maintains the supply chain system. This system allows customers to inspect transactions from raw materials to the end sale. This transaction data is recorded in ledgers as soon as any transactions occur on these multiple blockchain information dimensions, with verifiable updates. Customers are then able to track the detailed information of products, which increase their trust in the product characteristics (Tian, 2016).

By applying the entity "smart contract", supply chain actors ensure the authenticity and access right to products in the value chain. This entity enables the avoiding of any tampering or changes of product information in the entire supply chain. Through digital signature, a product can be transferred authentically from one party to another party within the supply chain. The evolution of blockchain enables managers to create shared, secured, decentralized ledgers and trustworthy supply networks. Moreover, this technology also supports peer-to-peer transaction between supply chain stakeholders, which helps to reduce the role of middlemen or intermediaries and facilitates supply chain risk and resiliency management within the network.

In addition to applying blockchain in the tracking of products or services or governance, it can be applied to sustainable supply chain management. Nowadays, there are growing concerns about building towards sustainable solutions. There are pressures from regulatory bodies, consumer associations and community service providers on businesses and their supply chains to improve the sustainability of their supply chains and their products (Zhu et al., 2018). From such business perspectives, it is necessary for supply chain managers to identify future supply chain implications in more detail by considering the effect of blockchain technology on sustainable supply chains.

\section{DISCUSSION AND CONCLUSIONS}

Blockchain technology is providing several new possibilities for organizations and, thus, is becoming an increasingly attractive tool to solve existing issues in various sectors in logistical networks (Sivula et al., 2018; Davidson et al., 2018; Mougayar and Buterin, 2016). Organizations strives to create blockchain-based innovations to achieve competitive advantage. Changing and adapting of logistical chains is commonly extremely hard. Organizations have put lots of effort and years of time into establishing supply chains and refining them (Li et al., 2018; Jiao et al., 2006; Smith et al., 2008). It can be concluded that inserting a new technology in the supply chain is not an easy task due to the integration challenges. The financial risks need to be analyzed carefully before utilization of blockchain technology in supply chain.

This research study has identified and presented the fundamental concept of blockchain technology, its types, architecture and implementation challenges and possibilities. In addition, the application of blockchain technology in supply chain management is also highlighted in this research study. Moreover, as part of the empirical study, this research analyzes three case companies regarding the possibility of implementing blockchain technology. These three case companies are engaged in various business domains such as wood construction, consulting and regional development and 
technology. From the study, it is noticed that all three companies are very enthusiastic about blockchain and have already implemented it in their supply chains apart from the wood construction company. The wood construction company is actively looking for possibilities to implement blockchain in its supply chain with the objective of better serving its customers through offering real-time traceability of its products.

Empirical studies indicate that there is further potential in implementing blockchain in many industries, which may ensure more value for their customers or end users. This is meant, for example, providing more informative data to the customer as well as recording information in the blockchain and utilizing in the future. However, it should be acknowledged that more qualitative and quantitative empirical evidence is required to increase the validity of the research. Moreover, additional testing and piloting of the applications of blockchain in supply chains in other industries can provide more valuable information to the end users through tracking and tracing.

From the presented research studies, it is also noticed that although blockchain provides many benefits for different kinds of industries, it is not yet ready for mass application. It is still under refinement with respect to both design and codebases, and there are no other established applications of it beside crypto currency so far. It is widely believed that the application of blockchain in supply chains will produce enhanced momentum and support real-time visibility, reduced complexity, improved accuracy and efficiency in the system, which ultimately helps the supply chain stakeholders to reduce costs and enhance trust.

There are limitations identified concerning the scope of this research study. The study is conducted with three case companies, which makes it difficult to generalize some parts of the concept and usability of blockchain to all supply chains. Testing and piloting of blockchain based systems is required in all industries to develop a solid standard for blockchain based activities in the supply chain and its management.

Further research is required for the blockchain and its utilization in blockchain. First, this paper has presented new business possibilities and challenges, which can be utilized, for instance, in testing and piloting of the blockchain solutions in different cases. Second, more research about the possible standards are required for blockchain utilization in supply chain including the standard development. Third, it be beneficial to research, how customers and other stakeholders could be connected to blockchain-enabled supply chains using crowdsourcing (c.f. Sivula \& Kantola, 2014). Fourth, more research of different blockchain technologies and their utilization in supply chain would be beneficial based on this research.

\section{REFERENCES}

Abeyratne, S.A., and Monfared, R.P. (2016). Blockchain ready manufacturing supply chain using distributed ledger. International Journal of Researching Engineering and Technology, 5(9), pp. 1-10.

Addo-Tenkorang, R., Helo, P.T., Shamsuzzoha, A., Ehrs, M., and Phuong, D. (2012). Logistics \& supply chain management tracking networks: Data-management system integration/interfacing issues. Paper presented at: Technology Management Emerging Technologies (PICMET), 2012 Proceedings of PICMET'12: IEEE Xplore, pp. 2198-2206.

Addo-Tenkorang, R., and Helo, P. (2016). Big data applications in operations/supply-chain management: A literature review. Computers \& Industrial Engineering, 101, pp. 528-543.

Apte, S., and Petrovsky, N. (2016). Will blockchain technology revolutionize excipient supply chain management?. Journal of Excipients and Food Chemicals, 7(4), pp. 768.

Bag, S., Telukdarie, A., Pretorius, J.H.C., and Gupta, S. (2018). Industry 4.0 and supply chain sustainability: framework and future research directions. Benchmarking: An International Journal.

Barbosa, M.W., Vicente, A.C., Ladeira, M.B., and de Oliveira, M.P.V. (2018). Managing supply chain resources with Big Data Analytics: A systematic review. International Journal of Logistics Research and Applications, 21(3), pp. 177-200.

Burgess, K., Singh, P.J., and Koroglu, R. (2006). Supply chain management: A structured literature review and implications for future research. International Journal of Operations \& Production Management, 26(7), pp. 703729.

Bussmann, O. (2017). A public or private blockchain? New Ethereum project could mean both. American Banker, 182(41).

Batwa, A. \& Norrman, A. (2020). A Framework for Exploring Blockchain Technology in Supply Chain Management. Operations and Supply Chain Management, 13(3), pp. 294-306

Crosby, M., Pattanayak, P., Verma, S., and Kalyanaraman, V. (2016). Blockchain technology: beyond bitcoin. Applied Innovation Review, 2, pp. 6-9.

Davidson, S., De Filippi, P., and Potts, J. (2018). Blockchains and the economic institutions of capitalism. Journal of Institutional Economics, 14(4), pp. 639-658.

Dickson, B. (2016). Blockchain has the potential to revolutionize the supply chain. Available from: https://techcrunch.com/2016/11/24/blockchain-has-thepotential-to-revolutionize-the-supply-chain/ [accessed Oct 18 2019].

Earls, A.R. (2016). Blockchain not a panacea for supply chain traceability, transparency. Available from: http://searchmanufacturingerp.techtarget.com/feature/Blockchain-not-a-panacea-for-supply-chain-traceability-transparency [accessed Oct 18 2019].

Francisco, K., and Swanson, D. (2018). The supply chain has no clothes: technology adoption of blockchain for supply chain transparency, Logistics, 2(1).

Gagnon, Y-C. (2010). The Case Study as Research Method: A Practical Handbook. Presses de l'Universite du Quebec, Quebec.

Groenfeldt, T. (2017) IBM and Maersk Apply Blockchain to Container Shipping. Available from: https://www.forbes.com/sites/tomgroenfeldt/2017/03/05/ibm-and-maersk-apply-blockchain-to- 
container-shipping/\#58bfd66b3f05 [accessed Oct 18 2019].

Gupta, V. (2017). A brief history of blockchain. Harvard business school publishing. Available from: https://hbr.org/2017/02/a-brief-history-of-blockchain [accessed Oct 18 2019].

Hancock, M., and Vaizey, E. (2016). Distributed ledger technology: Beyond block chain. London: Government Office for Science. Available from: https://assets.publishing.service.gov.uk/government/uploads/system/uploads/attachment_data/file/492972/gs-16-1-distributedledger-technology.pdf [accessed Oct 18 2019].

Helo, P., and Shamsuzzoha, A. (2020). Real-time supply chain - a blockchain architecture for project deliveries. Robotics and Computer-Integrated Manufacturing, 63.

Huang, Y-Y., and Handfield, R.B. (2015). Measuring the benefits of ERP on supply management maturity model: A "big data" method. International Journal of Operations \& Production Management, 35(1), pp. 2-25.

Ivanov, D., Dolgui, A., and Sokolov, B. (2018). The impact of digital technology and industry 4.0 on the ripple effect and supply chain risk analytics. International Journal of Production Research, 57(3), pp. 1-18.

Jordan, A., and Rasmussen, L.B. (2018). The role of blockchain technology for transparency in the fashion supply chain. Master's Thesis. Faculty of Culture and Society, Malmö University, Sweden.

Jiao, J., You, X., and Kumar, A. (2006). An agent-based framework for collaborative negotiation in the global manufacturing supply chain network. Robotics and Computer-Integrated Manufacturing, 22(3), pp. 239-255.

Kache, F., and Seuring, S. (2017). Challenges and opportunities of digital information at the intersection of Big Data Analytics and supply chain management. International Journal of Operations \& Production Management, 37(1), pp. 10-36.

Korpela, K., Hallikas, J., and Dahlberg, T. (2017). Digital supply chain transformation toward Blockchain integration. Paper presented at: Proceedings of the $50^{\text {th }}$ Hawaii International Conference on System Sciences.

Kshetri, N. (2018). Blockchain's roles in meeting key supply chain management objectives. International Journal of Information Management, 39, pp. 80-89.

Li, Z., Barenji, A.V., and Huang, G.Q. (2018). Toward a blockchain cloud manufacturing system as a peer to peer distributed network platform. Robotics and Computer-Integrated Manufacturing, 54, pp. 133-144.

Lieber, A. (2017). Trust in Trade: Announcing a new blockchain partner. Available from: https://www.ibm.com/blogs/blockchain/2017/03/trusttrade-announcing-new-blockchain-partner/ [accessed Oct 18 2019].

MacCarthy, B.L., Blome, C., Olhager, J., Srai, J.S., and Zhao, X. (2016). Supply chain evolution - theory, concepts and science. International Journal of Operations \& Production Management, 36(12), pp. 1696-1718.

Mainelli, M., and Milne, A. (2016). The impact and potential of blockchain on the securities transaction lifecycle. Available from: https://ssrn.com/abstract=2777404 [accessed Oct 18 2019].
Matthias, O., Fouweather, I., Gregory, I., and Vernon, A. (2017). Making sense of big data - can it transform operations management? International Journal of Operations \& Production Management, 37(1), pp. 37-55.

Maurer, B. (2017). Blockchains Are a Diamond's Best Friend: Zelizer for the Bitcoinmoment", In Money Talks: Explaining How Money Really Works. Edited by Bandelj F.F.W.N. Zelizer, V.A. Princeton University Press, Princeton.

Mohanta, B.K., Panda, S.S., and Jena, D. (2018). An Overview of Smart Contract and Use Cases in Blockchain Technology. Paper presented at: 9th International Conference on Computing, Communication and Networking Technologies (ICCCNT).

Morten, B. (2018). Understanding the value of big data in supply chain management and its business processes: Towards a conceptual framework. International Journal of Operations \& Production Management, 38(7), pp. 15891614.

Mougayar, W., and Buterin, V. (2016). The Business Blockchain: promise, practice, and application of the next Internet technology. John Wiley \& Sons Inc, New Jersey, USA.

Nakamoto, S. (2008). Bitcoin: a peer-to-peer electronic cash system. Available from: https://bitcoin.org/bitcoin.pdf [accessed Oct 18 2019].

Narayanan, A., Bonneau, J., Felten, E., Miller, A., and Goldfeder, S. (2016). Bitcoin and cryptocurrency technologies: a comprehensive introduction. Princeton University Press, Princeton.

Nguyen, Q.K. (2016). Blockchain - a financial technology for future sustainable development. Paper presented at: 3rd International Conference on Green Technology and Sustainable Development, pp. 24-25.

Papetti, A., Marconi, M., Rossi, M., and Germani, M. (2019). Web-based platform for eco-sustainable supply chain management. Sustainable Production and Consumption, 17 , pp. 215-228

Qiu, X., Luo, H., Xu, G., Zhong, R., and Huang, G.Q. (2015). Physical assets and service sharing for IoT-enabled supply hub in industrial park (ship). International Journal of Production Economics, 159, pp. 4-15.

Richey, R.G., Morgan, T.R., Lindsey-Hall, K., and Adams, F.G. (2016). A global exploration of big data in the supply chain. International Journal of Physical Distribution \& Logistics Management, 46(8), pp. 710-739.

Saberi, S., Kouhizadeh, M., Sarkis, J., and Shen, L. (2019). Blockchain technology and its relationships to sustainable supply chain management. International Journal of Production Research, Vol. 57(7), pp. 2117-2135.

Sadouskaya, K. (2017). Adoption of blockchain technology in supply chain and logistics. Bachelor's Thesis, Business Logistics, Kaakkois-Suomen Ammattikorkeakoulu Oy, Finland.

Shaiq, M., Alwi, S.K.K, Shaikh, S. and Zaman, Z. (2020). Quality Management as Driver of Vertical Integration in Service Chain: A Study of 3rd Party Logistics Industry. Operations and Supply Chain Management, 13(3), pp. 244-255. 
Sivula, A. \& Kantola, J. 2014. Combining crowdsourcing and Porter's value chain. International Journal of Advanced Logistics, 3(1-2), pp. 17-26.

Sivula, A., Shamsuzzoha, A., and Helo, P. (2018). Blockchain in logistics: mapping the opportunities in construction industry. Paper presented at: Proceedings of the International Conference on Industrial Engineering and Operations Management.

Skilton, P.F., and Robinson, J.L. (2009). Traceability and normal accident theory: How does supply network complexity influence the traceability of adverse events? Journal of Supply Chain Management, 45(3), pp. 40-53.

Smith, S., Petty, D., Trustrum, D., Labib, A., and Khan, A. (2008). A supply network-modelling system for a smallto medium-sized manufacturing company. Robotics and Computer-Integrated Manufacturing, 24(4), pp. 579584.

Smith, S.S. (2019). Blockchain, artificial intelligence and financial services. Springer International Publishing, Switzerland.

Stevens, G.C., and Johnson M. (2016). Integrating the supply chain ... 25 years on. International Journal of Physical Distribution \& Logistics Management, 46(1), pp. 19-42.

Steiner, J., and Baker, J. (2015). Blockchain: The solution for transparency in product supply chains. Available from: https://www.provenance.org/whitepaper [accessed Oct 18 2019].

Swan, M. (2015). Blockchain: Blueprint for a new economy. O'Reilly Media Inc, USA.

Tama, B.A., Kweka, B.J., Park, Y., and Rhee, K-H. (2017). A critical review of blockchain and its current applications. Paper presented at: International Conference on
Electrical Engineering and Computer Science (ICECOS).

Tian, F. (2016). An Agri-food Supply Chain Traceability System for China Based on RFID \& Blockchain Technology. Paper presented at: 13th International Conference on Service Systems and Service Management (ICSSSM).

Usama \& Ramish. (2020). Towards a Sustainable Reverse Logistics Framework / Typologies Based on Radio Frequency Identification (RFID). Operations and Supply Chain Management, 13(3), pp. 222-232.

Wamba, S.F., Ngai, E.W.T., Riggins, F., and Akter, S. (2017). Transforming operations and production management using big data and business analytics: Future research directions. International Journal of Operations \& Production Management, 37(1), pp. 2-9.

Williams, R. (2015). How Bitcoin's technology could make supply chains more transparent, Coindesk. Available from: http://www.coindesk.com/how-bitcoins-technology-could-make-supply-chains-more-transparent/ [accessed Oct 18 2019].

Yin, R.K. (2014). Case Study Research: Design and Methods, 5th edition. SAGE Publications Inc, California.

Zheng, Z., Xie, S., Dai, H., Chen, X., and Wang, H. (2017). An overview of blockchain technology: architecture, consensus, and future trends. Paper presented at: 2017 IEEE International Congress on Big Data (BigData Congress), pp. 557-567.

Zhu, Q., Sarkis, J., and Lai, K.-H. (2018). Regulatory policy awareness and environmental supply chain cooperation in china: a regulatory-exchange-theoretic perspective. IEEE Transactions on Engineering Management, 65(1), pp. 46-58.

Ari Sivula, PhD, is a Research and Development Manager in the School of Technology at the Seinäjoki University of Applied Sciences, Finland. Prior to his current position, he was acting as a University Lecturer, Head of the Master's Programme and Head of Industrial Management Department in the School of Technology and Innovations at the University of Vaasa, Finland. He received his MS in Computer Science from the University of Vaasa in 2011 and his PhD in Industrial Management from the University of Vaasa in 2016. He is holding several professional certifications and is experienced in software engineering, project and portfolio management, six sigma, regional and business development, innovation management and innovation ecosystems. He has been working in the public and private sectors in various roles and has managed multiple projects in different domains. His current research interests include innovation management, new product and service development, platform economy, and several other contemporary topics like blockchain and servitization.

\begin{abstract}
Ahm Shamsuzzoha has been working as a Tenure Track Professor, School of Technology and Innovation, University of Vaasa. He received his PhD in Industrial Management, School of Technology and Innovations, University of Vaasa, Finland in 2010 and his Master of Science degree (Mechanical Engineering) from the University of Strathclyde, Glasgow, UK. His major research and teaching interest lies in the area of project and portfolio management, enterprise collaborative networks, operations management, new product and service development, logistics and supply chain management and several other contemporary topics like blockchain and servitization. He has published several research articles in both reputed refereed international journals and conferences.
\end{abstract}

Petri Helo is Professor of Industrial Management, Logistics Systems and the head of Networked Value Systems research group, at School of Technology and Innovations, University of Vaasa, Finland. His research addresses the management of supply demand networks and use of information technology in operations. Prof. Helo is also partner and board member at Wapice Ltd, a software solution provider of CPQ and IoT solutions. 